\title{
Burnout and Coping Skills amongst Medical Officers: A study in a tertiary hospital in Malaysia
}

\author{
Nur Faizah Ali¹, Nor Jannah Nasution Raduan¹, Zaliha Ismail², Salmi Razali \\ 1 Department of Psychiatry, ${ }^{2}$ Department of Public Health Medicine, Faculty of Medicine, \\ Universiti Teknologi MARA (UiTM), 47000 Sg. Buloh, Selangor Malaysia \\ faiess82@gmail.com, jannahraduan@gmail.com, drzie65@gmail.com, drsalmi@gmail.com \\ Tel: +60193505041
}

\begin{abstract}
Burnout among doctors is hazardous, leading to stress which results in poor decision making and exposure to medical errors. This study aims to improve the knowledge gap of the issues of burnout and coping skills among medical officers. This study is a cross-sectional study involving 250 medical officers, using universal sampling. Of the total 250 participants, $63(25.2 \%)$ were burnout. The presence of burnout was significantly associated with dysfunctional coping skills $(t=-4.96 ; p<0.001)$. Burnout is prevalent among medical officers. It is vital to take actions that can promote good mental health in the form of coping skills and resilience training.
\end{abstract}

Keywords: burnout; coping skills; doctors; medical

eISSN: 2398-4287 @ 2019. The Authors. Published for AMER ABRA cE-Bs by e-International Publishing House, Ltd., UK. This is an open access article under the CC BYNC-ND license (http://creativecommons.org/licenses/by-nc-nd/4.0/). Peer-review under responsibility of AMER (Association of Malaysian Environment-Behaviour Researchers), ABRA (Association of Behavioural Researchers on Asians) and cE-Bs (Centre for Environment-Behaviour Studies), Faculty of Architecture, Planning \& Surveying, Universiti Teknologi MARA, Malaysia.

DOI: https://doi.org/10.21834/e-bpj.v4i12.1940

\subsection{Introduction}

The prevalence of burnout is worrying. Almost one in every three physicians is experiencing burnout at any given time (Shanafelt et al., 2012). One of the reasons for such a high level of exhaustion was because of the long working hours. This eventually causes severe stress and work-life imbalance (Shanafelt et al., 2012). Ineffective stress management may lead to various negative implications not only to the patients and family but also to the nation at large.

The term "burnout" was introduced by an American Psychologist, Herbert Freudenberger in 1970s. The most widely accepted concept of burnout was suggested by Maslach \& Jackson (1981) and elaborated further by Cordes \& Dougherty (1993) who described burnout in three dimensions: Emotional Exhaustion, Depersonalisation or Cynicism and low Personal Accomplishment. Emotional Exhaustion (EE) is the feeling of being emotionally overextended and exhausted caused by the working condition. Depersonalisation (DP) is the feeling of being detached and impersonal towards the people they encounter within one's work. Personal Accomplishment (PA) is a measure to assess perception of competence and achievement when one works with people (Maslach, Jackson, \& Leiter, 1996; Schaufeli \& Enzmann, 1998). Individuals particularly medical doctors who are facing daily demanding challenges in their work and are at risk of chronic stress can experience burnout. Burnout is known to have negative consequences at an individual level or during interaction with other people such as the patients, carers and other colleagues (Kumar, 2016)

Several scholars have suggested their ways of classifying coping skills. The widely used categorization of coping skills was introduced by Folkman (1984) and Folkman \& Lazarus (1980), who divided the coping skills into problem-focused and emotion-focused. Cooper, Katona, and Livingston (2008) introduced another type of coping; the dysfunctional coping skills. Researchers commonly use these three types of coping skills using the Brief COPE questionnaire (Carver, 1997).

eISSN: 2398-4287 @ 2019. The Authors. Published for AMER ABRA cE-Bs by e-International Publishing House, Ltd., UK. This is an open access article under the CC BYNC-ND license (http://creativecommons.org/licenses/by-nc-nd/4.0/). Peer-review under responsibility of AMER (Association of Malaysian Environment-Behaviour Researchers), ABRA (Association of Behavioural Researchers on Asians) and cE-Bs (Centre for Environment-Behaviour Studies), Faculty of Architecture, Planning \& Surveying, Universiti Teknologi MARA, Malaysia. DOI: https://doi.org/10.21834/e-bpj.v4i12.1940 
An individual most often uses a combination of more than one type of coping. The problem-focused coping skills are employed when one seeks to solve a problem and modify the actual reason that causes stress in the first place (Yusoff, Ying Jie, \& Esa, 2011). In situations where the issues do not have any specific solution and need endurance, the emotion-focused coping skills should be best employed (Folkman, 1984; Folkman \& Lazarus, 1980). As for dysfunctional coping skills, it is the type of coping that can make a person have more difficulty in overcoming his/her problem and hence, the escalation of stress occurs.

In Malaysia, medical officers function as the main backbone of the routine clinical tasks that ensure the patients and family receive the highest standard of care. It is imperative to safeguard their wellbeing so that their personal physical and mental health are taken care of, apart from the efficient healthcare service delivery. To date, not many studies were conducted to assess burnout and its association with coping skills among the medical officers in order to formulate appropriate stress management. Respective authorities can use the results from the studies to plan the evidence-based intervention for this group of people such as an initiative to address the problem efficiently, providing more workforce to a specific department or conducting coping skills training among the medical officers.

There is a gap in understanding level of burnout and coping skills among medical officers. Therefore, the objectives of this research are to determine the prevalence of burnout, to describe the domains of burnout and to identify the relationship between different types of coping skills and burnout among medical officers working in a tertiary hospital in Malaysia.

\subsection{Literature Review}

\subsection{Definition and Assessment of Burnout}

In the year 1974 and 1996, a psychiatrist and a clinical psychologist described burnout in their published papers about burnout (Freudenberger, 1974; Maslach et al., 1996). Since then, more studies came along discussing the definition, factors associated with it, and how to manage burnout. Freudenberger (1974) focused more on the clinical aspect as to how to assess burnout, how to prevent it from happening as well as focusing on the possible treatment options. Other researchers, on the other hand, focused more on the theory of burnout and evidence-based (Maslach \& Jackson, 1981; Maslach, Leiter, \& Schaufeli, 2008).

There was also debate as to whether to define burnout as a multidimensional or unidimensional construct (Brenninkmeijer \& Vanyperen, 2003). The earlier works suggested three dimensions of burnout; Emotional Exhaustion, Depersonalisation and Personal Accomplishment (Maslach \& Jackson, 1981; Maslach et al., 1996). Although the multidimensional theory of burnout becomes the primary approach in burnout studies, more people found the need to look at it in a unidimensional approach. It is useful especially if people are trying to study the complicated relationship between burnout and other variables.

\subsection{Burnout and Medical Doctors}

Burnout is associated with diminished efficiency and high turnover rate as well as causing reduced clients' satisfaction (Pakenham \& Stafford-Brown, 2012). In Malaysia, a study done in Universiti Kebangsaan Malaysia Medical Centre (UKMMC) demonstrated that any element that contributed to job stress such as highly demanding tasks, increased workload and the conflict between work and social/family life could cause psychological distress. Psychological distress can potentially lead to burnout among the doctors (Tan, Jong, Jamaludin, Jamaludin, \& Shah, 2013).

Although burnout can affect people from all different kinds of job scope, the work related to human services and caring for other people such as teacher, nurses and doctors are of higher risk (Roslan, S., Sharifah, \& Thirumalai, 2012). Doctors have a higher susceptibility for burnout, probably due to the nature of their training and work.

\subsection{Coping Skills and Burnout}

Coping and stress cannot be separated, and both of the concepts are related to change. Stress in itself is the change of the equilibrium in a person's life and by utilising coping skills, the person can change this disequilibrium (Folkman \& Lazarus, 1985). It can be done by the constant cognitive change and adaptation of the behaviour of the person who tries to manage the situation where the excess internal or the external demands becomes too much (Folkman \& Lazarus, 1980). The excess stimuli or the stressful situation can be from the current or past experiences. Both can trigger the reaction of coping (Goretti, Zipoli, Portaccio, Razzolini, \& Amato, 2010).

Different authors have investigated ways of classifying coping skills. The widely used categorization of coping skills is to divide the skills into problem-focused and emotion-focused by Folkman (1984) and Folkman \& Lazarus (1980). Cooper et al. (2008) introduced the dysfunctional coping skills. These three types of coping skills can be measured in research studies using the Brief COPE questionnaire (Carver, 1997). Other concepts used to describe the construct of coping include 'engagement vs. disengagement', 'control vs escape', 'behavioural vs cognitive coping' and 'social vs solitary' and many others (Compas, Connor-Smith, Saltzman, Thomsen, \& Wadsworth, 2001; Latack, J. C., \& Havlovic, 1992).

\subsection{Methodology}

This study is a cross-sectional study involving medical officers in one of the tertiary hospitals in Klang Valley, Malaysia using a universal sampling method.

A total of 408 medical officers registered doctors (clinical and non-clinical) were approached by the researcher during a weekly Hospital Continuous Medical Education (CME) and departmental CME from March until May 2017. The participants' information sheet and the study risk and benefit were explained by the researcher. Those who gave written informed consent recruited for the study. A set 
of questionnaires were provided before the CMEs. They were collected after the CMEs. Those who had not finished answering the questions, they were followed up at the departmental level. Those who were not in the CMEs (for example in operation theatre, on leave, etc.) did not take part.

Inclusion criteria include medical officers registered in the hospital database at the time of the study, aged 18 and above and who were able to understand, read and communicate in English or Bahasa Malaysia. Medical officers based in the studied hospital but at the time of the study were in other hospitals or health facilities for continuous learning and who have a previous history of psychiatric illness were excluded.

Maslach Burnout Inventory (MBI-HSS) was used to measure burnout, and the operationalized definition of burnout in this study follows description used by former groups of researchers; Brenninkmeijer \& Vanyperen (2003); Sabki \& Zainal (2015) as well as Maslach et al. (1996). Burnout was defined by these researchers as a "high" score ( $\geq 75$ th percentile) of the EE total score plus the overall score of DP. Assessment of the severity of three dimensions of burnout; EE, DP and PA were done to determine low, moderate and high levels of each burnout dimensions. Cronbach's alpha for the EE, DP and PA in the present study were $0.880,0.790$, and 0.735 , respectively. Coping skills were measured using the Brief COPE, which consists of 28 items. The three types of coping skills were: i) problem-focused, ii) emotion-focused coping, and iii) dysfunctional coping (Cooper et al., 2008; Folkman, 1984). All questionnaires distributed to the participants were according to their preference of either Malay or English versions.

Ethical approval obtained from Ethical Board of Research Committee of Universiti Teknologi MARA (UiTM) and the National Medical Research and Ethics Committee (MREC) of the Ministry of Health (MOH), Malaysia via the National Medical Research Registry (NMRR).

All data analysis was performed using International Business Machines (IBM®) Statistical Package for Social Sciences (SPSS® version 24) for Window 10. Descriptive statistics used to describe sociodemographic factors, burnout, and coping skills. Bivariate analysis (chi-square test and independent t-test) and multivariate analysis (linear regression) used to study the prevalence of burnout, coping skills and the association between the two factors.

\subsection{Findings}

A total of 390 questionnaires distributed. Of the total, 255 participants consented and submitted their answered questionnaires. The response rate was $65.38 \%$. Five questionnaires rejected due to incompletion.

There were more female than male medical officers ( $32 \%$ male and $68 \%$ female) with the mean age of $30.37 \pm 2.80$ years. More than half were Malays $(135 ; 54 \%)$ and married $(145 ; 58 \%)$. About two-thirds of the medical officers had no children $(160 ; 64 \%)$. In terms of the cluster of the department, the medical and surgical clusters had about the same number of medical officers which was significantly higher than the ones on laboratory medicine and administration cluster. The mean duration of service in months as a medical officer was $54.3 \pm 42.39 .81$ (32.4\%) of the medical officers were at the time of study undertaking postgraduate training (refer Table 1).

Table 1. The socio-demographic factors of the medical officers

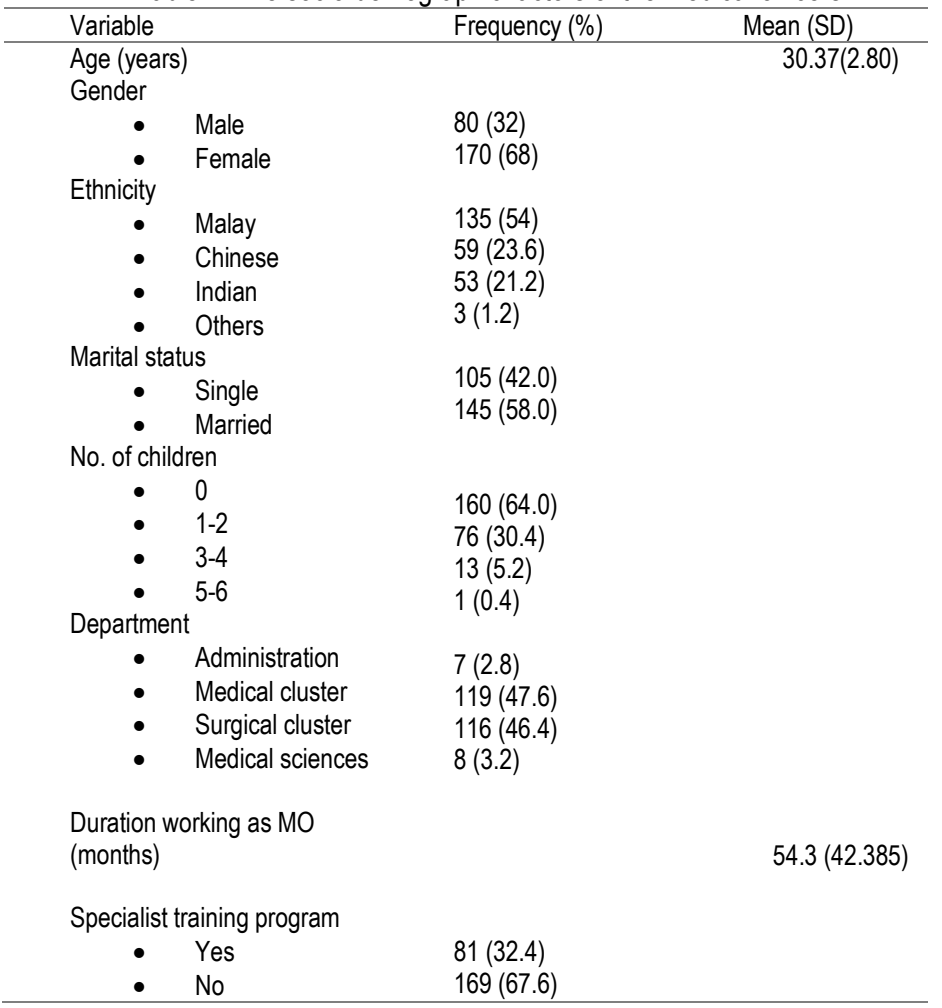


This study found the cut-off point for a total score of the presence of burnout (i.e. level of Emotional Exhaustion and Depersonalisation more than 75 percentiles) was at $\geq 41$ (refer Table 3).

Table 3. Scores of the MBI-HSS and its sub-scales

\begin{tabular}{cccccccccc}
\hline Dimensions & $\mathrm{N}$ items & Mean (SD) & Range & 25 th percentiles & 50th percentiles & $7^{\text {th }}$ percentiles & $\begin{array}{c}\text { Low } \\
\mathrm{n}(\%)\end{array}$ & $\begin{array}{c}\text { Moderate } \\
\mathrm{n}(\%)\end{array}$ & $\begin{array}{c}\text { High } \\
\mathrm{n}(\%)\end{array}$ \\
\hline $\mathrm{EE}$ & 9 & $23.41(10.66)$ & $2-51$ & 16.0 & 32.0 & 31.0 & $67(26.8)$ & $87(34.8)$ & $96(38.4)$ \\
$\mathrm{DP}$ & 5 & $8.18(5.95)$ & $0-30$ & 4.0 & 7.0 & 12.0 & $118(47.2)$ & $77(30.8)$ & $55(22.0)$ \\
PA & 8 & $31.38(7.424)$ & $14-48$ & 26.0 & 31.0 & 37.3 & $128(51.2)$ & $77(30.8)$ & $45(18.0)$ \\
$\begin{array}{c}\text { Presence of burnout } \\
\text { (EE+DP) }\end{array}$ & 14 & $31.59(15.24)$ & $4-77$ & 20.0 & 32.0 & 41.0 & & & \\
\hline
\end{tabular}

$\mathrm{EE}=$ Emotional Exhaustion, $\mathrm{DP}=$ Depersonalisation, $\mathrm{PA}=$ Personal Accomplishment

Prevalence of burnout among the medical officers in a tertiary hospital in Malaysia was $25.2 \%(n=63)$ (refer to Figure 1). In the EE dimension, more than a third (38.4\%) of medical officers scored high. For the DP dimension, only $22 \%$ reported high score, and for PA dimension, the majority (51.2\%) scored low (refer Figures 2 to 4).

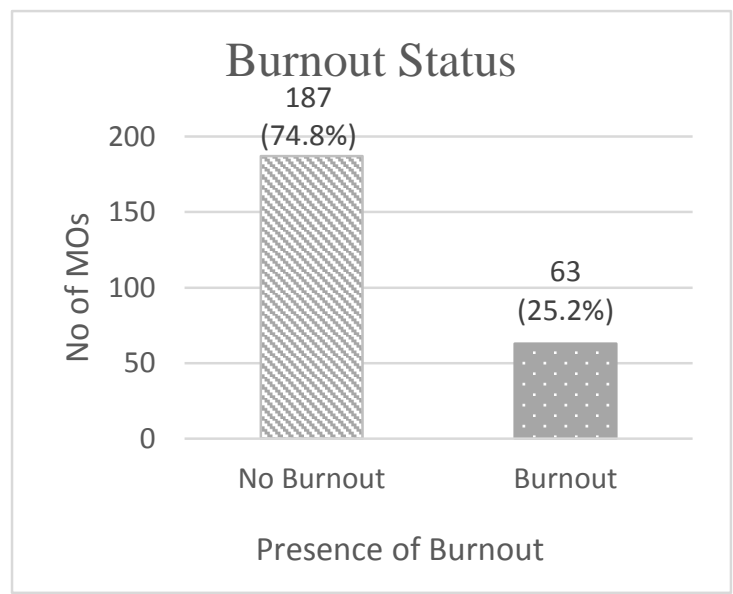

Figure 1: The presence of burnout

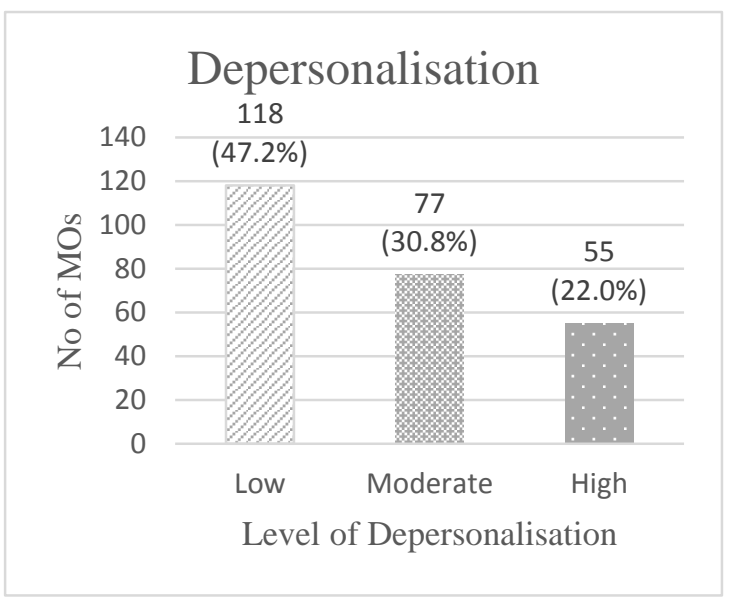

Figure 3: Level of Depersonalisation

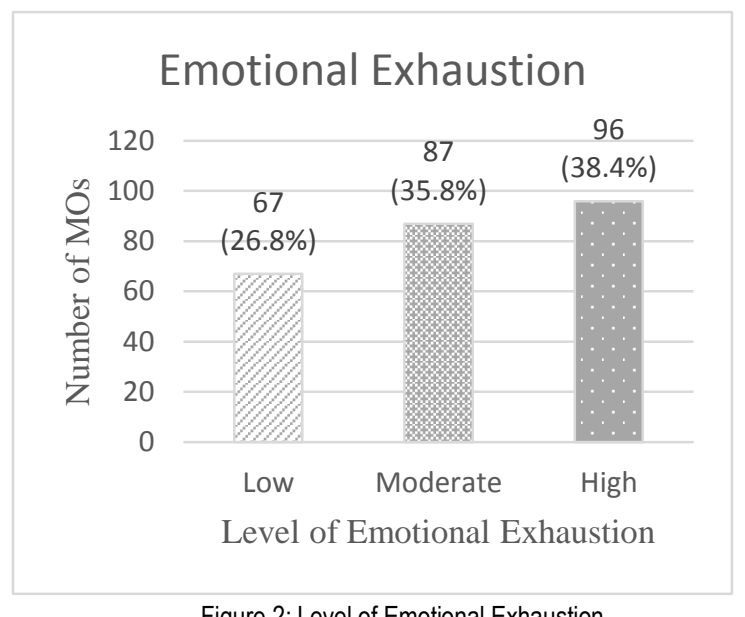

Figure 2: Level of Emotional Exhaustion

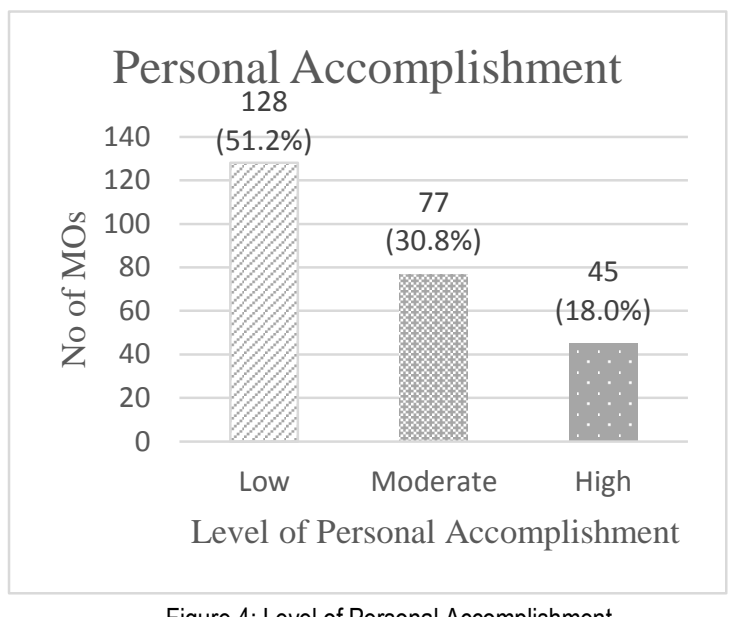

Figure 4: Level of Personal Accomplishment

There was a significant difference in the mean score of dysfunctional coping among those having burnout and no burnout group $(t=-4.96, p=<0.001)($ refer Table 4$)$.

Table 4. The Association between coping skills and burnout

\begin{tabular}{|c|c|c|c|c|c|c|}
\hline \multirow{2}{*}{ Method } & \multirow{2}{*}{ Mean (SD) } & \multirow{2}{*}{ Types of coping skills } & \multicolumn{2}{|c|}{ Mean (SD) } & \multirow{2}{*}{$t$ statistic(df) } & \multirow{2}{*}{$p$ value* } \\
\hline & & & Burnout & No Burnout & & \\
\hline Active coping & $5.76(1.36)$ & \multirow{3}{*}{ Problem focused } & \multirow{3}{*}{$16.16(3.42)$} & \multirow{3}{*}{$16.19(2.88)$} & \multirow{3}{*}{$0.07(248)$} & \multirow{3}{*}{0.95} \\
\hline Instrumental support & $5.36(1.60)$ & & & & & \\
\hline Planning & $5.83(1.34)$ & & & & & \\
\hline Emotional support & $5.46(1.76)$ & \multirow{2}{*}{ Emotion focused } & \multirow{2}{*}{$26.90(4.77)$} & \multirow{2}{*}{$27.93(5.16)$} & \multirow{2}{*}{$1.39(248)$} & \multirow{2}{*}{0.17} \\
\hline Positive reinterpretation & $5.88(1.34)$ & & & & & \\
\hline
\end{tabular}




\begin{tabular}{ll}
\hline Humour & $4.28(1.72)$ \\
\hline Acceptance & $5.99(1.33)$ \\
\hline Religion & $6.06(1.80)$ \\
\hline Mental disengagement & $5.44(1.37)$ \\
\hline Denial & $2.72(1.09)$ \\
\hline Substance abuse & $2.20(0.82)$ \\
\hline Behavioural disengagement & $2.98(1.20)$ \\
\hline Venting of emotion & $4.59(1.41)$ \\
\hline Self-blame & $4.25(1.53)$ \\
\hline
\end{tabular}

Multivariate analysis of coping skills and burnout concluded that medical officers who adopt the dysfunctional coping skills have 1.1 times the odds of having burnout than those who do not. Medical officers who employed emotion-focused are $8 \%$ less likely to get burnout which can be a protective factor (refer Table 5)

\begin{tabular}{cccccc}
\multicolumn{6}{c}{ Table 5. Multivariate analysis of associated factors with burnout } \\
\hline Variables & B & SE & $\begin{array}{c}\text { Adjusted OR } \\
(95 \% \mathrm{Cl})\end{array}$ & $\begin{array}{c}\text { Wald statistics } \\
\text { (df) }\end{array}$ & $P$-value \\
\hline Emotion-focused coping skills & -0.82 & 0.03 & $0.92(0.86,0.98)$ & $6.08(1)$ & 0.014 \\
\hline Dysfunctional coping skills & 0.19 & 0.04 & $1.2(1.12,1.30)$ & $22.75(1)$ & $<0.001$ \\
\hline
\end{tabular}

\subsection{Discussion}

This study found a significant percentage of burnout among the medical officers (25.2\%) and its main contributing factors; being single, having psychological distress. The percentage of burnout we found is consistent with a study in a public hospital in South Africa which documented $26.3 \%$ of burnout among the 205 number of participants (Sirsawy et al., 2016). Both study settings were public hospitals. In a more well-resourced country such as the Netherlands, Prins et al., (2010), who investigated a more significant number of respondents (5140 respondents), the rate of burnout was similar. In contrary, Shanafelt et al. (2012), Wu et al. (2013), found a higher prevalence of burnout compared to our findings which may be due to bigger sample size.

However, a study in Europe by Soler et al. (2008) and another in Yemen by Al-Dubai \& Rampal (2010) showed much lower prevalence rate compared to the current study. It is worth to note that the different studies in burnout used different definition to identify the presence of burnout, for example, taking into consideration only the Emotional Exhaustion as the determinant of burnout (Aiken, Clarke, Sloane, \& Sochalski, 2002). The differences may be one of the factors contributing to discrepancies in the rate of prevalence.

The burnout prevalence of medical officers is similar to that of doctors going through housemanship (Sabki \& Zainal, 2015). However, studies among medical students showed as high as $67.9 \%$ of burnout (Al-Dubai et al., 2011; Chin et al., 2016), much higher compared to medical officers. This finding could be due to the difference in the dynamics of being students compared to those who already started working.

To the best of our knowledge, this is the first study exploring the association between coping skills and burnout among the medical officers in Malaysia. Medical officers are the main players of the medical services in Malaysia. They learn to have more responsibilities in clinical practice, administrative work, and undergo training to be specialists with additional commitments and expectations. At this stage, medical officers need to adjust to the new working time, where they work at longer hours during on-call contrary to the working system of Houseman's Flexi Hour Shift System, during internship, which found to reduce job-related stress (Thillainathan, 2011).

Emotion-focused coping skills are protective against burnout ( $\mathrm{OR}=0.92)$, whereby those who employed emotion coping skills were $8 \%$ less likely to have burnout. It helps the medical officers to cope in situations where no specific solution is available. Emotion-focused coping skills may include seeking emotional support, positive reinterpretation, acceptance, denial, and turning to religion (Cooper et al., 2008; Folkman, 1984).

Dysfunctional coping skills found to be significantly associated with burnout in this study. This finding does not come as a surprise because of previous studies showing dysfunctional coping skill as the cause of distress and a source of stress (Cooper et al., 2006; Yusoff et al., 2011). It is essential to note the possibility of burnout medical officers in this study, not adequately trained in healthy coping skills in dealing with their daily stress. These medical officers highly likely adopt the dysfunctional coping style due to lack of experience. Many of them are still in their early career path and had not developed the maturity to process their own emotion and behaviour. The lack of proper training of healthy coping skill in the formal curriculum in Medicine too can serve as the contributing factor of them lacking the appropriate skills. Only recently, such curriculum introduced in most medical school in the United States (Shanafelt \& Dyrbye, 2012). In other places, no specific course incorporated in the curriculum that promotes self-health and wellness, although these skills are vital to cultivate the behaviour that ensures resilience throughout their medical career.

There are several approaches available in addressing the issue of burnout. A recent guide from the World Economic Forum suggests that interventions should take a 3-pronged approach: to protect mental health by reducing work-related risk factors; to promote mental health by developing the positive aspects of work and the strength of employees, and to address mental health problems regardless of cause. Periodical psychological assessment, particularly the level of burnout among doctors, should be 
incorporated to protect their best interest. Screening the doctors with the burnout tools should be feasible, and results need to be accessible by specific centres, for example the hospital, universities or the health clinic. This action can enable early interventions.

Authorities handling the welfare of doctors should look into incorporating the training of self-health and useful coping strategies in the curriculum throughout the medical practice. Short courses of maintaining good physical and psychological health are also vital. Methods such as tackling the specific issues at the individual level (for example family history, workload, number of on calls, monthly salary, financial difficulties), the environmental level (for instance conducive working environment) and the organizational level (for example types of leadership) need to be encouraged. These efforts need to be supported by the government or by the national blue ocean strategy (NBOS) from the financial and expertise point of view.

There were a few areas of improvement in this study. First, the study design itself that is the cross-sectional and sampling method using the universal (non-probability) sampling. Second, participants in this study were limited to the involvement of medical officers in one public hospital in Malaysia and did not represent the whole population of medical officers in Malaysia. No diagnostic tool was used. Lastly, medical officers who were rushing to complete their daily task might not take their time to answer the question carefully. Among recommendations for future study include using longitudinal cohort study to provide a better perspective of the issues of burnout and gives better clarification on information, stronger findings and associations between coping skills and burnout amongst the medical officers and using probability sampling method such as randomized sampling, to improve the generalizability. Multi-centre studies on medical officers involving rural area as well as other settings such as medical-related research centres, health clinic and private practices/hospital could be conducted throughout Malaysia to have a generalised projection.

\subsection{Conclusions}

Burnout is also prevalent among medical officers, not just among medical sudents or junior doctors. This issue needs to be addressed seriously because it will affect the healthcare services negatively. Dysfunctional coping skills contribute to burnout while emotionfocused coping skills are protective against burnout. In order to overcome this problem, medical officers are encouraged to manage their problems or stress through healthy ways of coping. Knowledge on mental health awareness, resilience competency training, mindfulness training, self compassion, support group and other intervention programs are beneficial to prevent burnout. In the future, further studies on various effective intervention to overcome this problem are very much needed.

\section{Acknowledgement}

We would like to extend our appreciation to the Ministry of Health, Malaysia and Universiti Teknologi MARA for their involvement and cooperation to make this study a success.

\section{References}

Aiken, L. H., Clarke, S. P., Sloane, D. M., \& Sochalski, J. (2002). Hospital Nurse Staffing and Patient Mortality, Nurse Burnout, and Job Dissatisfaction. Journal of American Medical Association, 288(16), 1987-1993.

Al-Dubai, S. A. R., Al-Naggar, R., AL-Shagga, M., \& Rampal, K. (2011). Stress and Coping Strategies of Students in a Medical Faculty in Malaysia. Malaysian Journal of Medical Science, 18(3), 57-64.

Al-Dubai, S. A. R., \& Rampal, K. G. (2010). Prevalence and associated factors of burnout among doctors in Yemen. Journal of Occupational Health, 52, 58-65. https://doi.org/10.1539/joh.08030

Brenninkmeijer, V., \& Vanyperen, N. (2003). How To Conduct Research on Burnout: Advantages and Disadvantages of a Unidimensional Approach in Burnout Research. Occup Environ Med, 60, $16-20$.

Carver, C. S. (1997). You Want to Measure Coping but Your Protocol Too Long: Consider the BRIEF Cope. International Journal of Behavioral Medicine, 4(1), 92-100. https://doi.org/10.1207/s15327558ijbm0401_6

Chin, R., Chua, Y. Y., Chu, M. N., Mahadi, N., Yusoff, M., Wong, M., \& Lee, Y. Y. (2016). Prevalence of Burnout among Universiti Sains Malaysia Medical Students. Education in Medicine Journal, 8(3), 61-74. https://doi.org/10.5959/eimj.v8i3.454

Compas, B. E., Connor-Smith, J. K., Saltzman, H., Thomsen, A. H., \& Wadsworth, M. E. (2001). Coping With Stress During Childhood and Adolescence: Problems, Progress And Potential in Theory and Research. Psychological Bulletin, 127, 87-127. https://doi.org/10.1037//0033-2909.127.1.87

Cooper, C., Katona, C., \& Livingston, G. (2008). Validity and Reliability of the Brief COPE in Carers of People With Dementia. The Journal of Nervous and Mental Disease, 196(11), 838-843. https://doi.org/10.1097/NMD.0b013e31818b504c

Cooper, C., Katona, C., Orrell, M., \& Livingston, G. (2006). Coping Strategies and Anxiety in Caregivers of People with Alzheimer's Disease : The LASER-AD Study. Journal of Affective Disorders, 90, 15-20. https://doi.org/10.1016/j.jad.2005.08.017

Cordes, C. L., \& Dougherty, T. W. (1993). A Review and an Integration on Job Burnout. Academy of Management Review, 18(4), 621-656.

Folkman, S. (1984). Personal Control and Stress and Coping Processes: A Theoretical Analysis. Journal of Personality and Social Psychology, 46(4), 839-852. https://doi.org/10.1037/0022-3514.46.4.839 
Folkman, S., \& Lazarus, R. S. (1980). An Analysis of Coping in a Middle-Aged Community Sample. Journal of Health and Social Behavior, 21(3), 219-239.

Folkman, S., \& Lazarus, R. S. (1985). If It Changes It Must Be A Process: Study of Emotion and Coping During Three Stages of A College Examination. Journal of Personality and Social Psychology, 48(1), 150-170. https://doi.org/10.1037/0022-3514.48.1.150

Freudenberger, H. J. (1974). Staff Burn-Out. Journal of Social Issues, 30(1), 159-165. https://doi.org/10.1111/j.1540-4560.1974.tb00706.x

Goretti, B., Zipoli, V., Portaccio, E., Razzolini, L., \& Amato, M. P. (2010). Coping Strategies , Cognitive Impairment, Psychological Variables and Their Relationship with Quality of Life in Multiple Sclerosis. Neurological Sciences, 31(2), 227-230. https://doi.org/10.1007/s10072-010-0372-8

Kumar, S. (2016). Burnout and Doctors : Prevalence , Prevention and Intervention. Healthcare, 4(37), 1-9. https://doi.org/10.3390/healthcare4030037

Latack, J. C., \& Havlovic, S. J. (1992). Coping with Job Stress: A Conceptual Evaluation Framework for Coping Measures. Journal of Organizational Behavior, 13, 479508.

Maslach, C., \& Jackson, S. (1981). The measurement of experienced Burnout. Journal of Occupational Behavior, 2, 99-113. https://doi.org/10.1002/job.4030020205

Maslach, C., Jackson, S. E., \& Leiter, M. P. (1996). Maslach Burnout Inventory Manual (3rd ed.). California, CA: Consulting Psychologists.

Maslach, C., Leiter, M. P., \& Schaufeli, W. (2008). The Oxford Handbook of Organizational Well Being. (Susan Cartwright and Cary L. Cooper, Ed.). Oxford University Press. https://doi.org/10.1093/oxfordhb/9780199211913.003.0005

Pakenham, K. I., \& Stafford-Brown, J. (2012). Stress in Clinical Psychology Trainees : A Review of Current Research and Future Directions. Australian Psychologist, 47 , 147-155. https://doi.org/10.1111/j.1742-9544.2012.00070.x

Peltzer, K., Mashego, T., \& Mabeba, M. (2003). Short Communication : Occupational Stress and Burnout Among South African Medical Practitioners. Stress and Health, 19, 275-280. https://doi.org/10.1002/smi.982

Prins, J. T., Hoekstra-Weebers, J. E. H. M., Gazendam-Donofrio, S. M., Dillingh, G. S., Bakker, A. B., Huisman, M., ... Van Der Heijden, F. M. M. A. (2010). Burnout and Engagement Among Resident Doctors in the Netherlands: A National Study. Medical Education, 44, 236-247. https://doi.org/10.1111/j.1365-2923.2009.03590.x

Roslan, S., Sharifah, M. N., \& Thirumalai, V. N. (2012). The Burnout Phenomenon : Changes in Psychosocial Profiles of Secondary School Teachers. Journal of Social Science and Humanities, 20(S), 157-174.

Sabki, Z., \& Zainal, N. (2015). Exploring Burnout Among Malaysian Junior Doctors Using the Abbreviated Maslach Burnout Inventory. Malaysian Journal of Psychiatry, 24(1), 1-10.

Schaufeli, W., \& Enzmann, D. (1998). The burnout compan- ion to study and practice: a critical analysis. London: Taylor \& Francis.

Shanafelt, T. D., Boone, S., Tan, L., Dyrbye, L. N., Sotile, W., Satele, D., ... Oreskovich, M. R. (2012). Burnout and satisfaction with work-life balance among US physicians relative to the general US population. Archives of Internal Medicine, 172(18), 1377-1385. https://doi.org/10.1001/archinternmed.2012.3199

Shanafelt, T., \& Dyrbye, L. (2012). Oncologist Burnout: Causes, Consequences, and Responses. Journal of Clinical Oncology, 30(11), $1235-1241$. https://doi.org/10.1200/JCO.2011.39.7380

Sirsawy, U., Steinberg, W. J., \& Raubenheimer, J. E. (2016). Levels of Burnout Among Registrars and Medical Officers Working at Bloemfontein Public Healthcare Facilities in 2013. South African Family Practice, 1(1), 1-6. https://doi.org/10.1080/20786190.2016.1198088

Soler, K. J., Yaman, H., Esteva, M., Dobbs, F., Desgranges, P., Moreau, A., ... Sa Azeredo, Z. D. A. (2008). Burnout in European Family Doctors : The EGPRN Study. Family Practice-An International Journal, 25(4), 245-265. https://doi.org/10.1093/fampra/cmn038

Tan, M. K., Jong, S. C., Jamaludin, N. A., Jamaludin, N. S., \& Shah, S. A. (2013). Physician , Heal Thyself : The Paradox of Anxiety Amongst House Officers and Work in a Teaching Hospital. Asia Pasific Psychiatry, 5, 74-81. https://doi.org/10.1111/appy.12048

Thillainathan, S. (2011). Implementation of Flexi Hours for House Officers. Retrieved July 1, 2017, from www.moh.gov.my/attachments/8065

Wu, H., Liu, L., Wang, Y., Gao, F., Zhao, X., \& Wang, L. (2013). Factors Associated With Burnout Among Chinese Hospital Doctors : A Cross-sectional Study. BMC Public Health, 13(786), 1-8. https://doi.org/10.1186/1471-2458-13-786

Yusoff, M. S. B., Yee, L. Y., Wei, L. H., Siong, T. C., Hon, L., Bin, L. X., ... Rahim, A. (2011). A Study On Stress, Stressors and Coping Strategies Among Malaysian Medical Students. International Journal of Students' Research, 1(2), 45-50.

Yusoff, M. S. B., Ying Jie, T., \& Esa, A. R. (2011). Stress, stressors and coping strategies among house officers in a Malaysian hospital. ASEAN Journal of Psychiatry, 12(1), 85-94. 